\title{
The Crisis Approach
}

\author{
Arjen Boin, Paul 't Hart and Sanneke Kuipers
}

\section{Contents}

2.1 Introduction: Crisis and Disaster 23

2.2 The Nature of Crisis

2.2.1 Theoretical Perspectives

2.3 The Ubiquity of Crisis

2.4 Crisis Management: Crucial Challenges for Leadership

2.4.1 Early Detection

2.4.2 Sense Making

2.4.3 Making Critical Decisions

2.4.4 Crisis Coordination......

2.4.5 Meaning Making

2.4.6 Accounting for Performance ................ 33

2.4.7 Learning Lessons

2.5 Conclusion: The Crisis Approach

Reconsidered

References

\subsection{Introduction: Crisis and Disaster}

The terms 'crisis' and disaster' are often used synonymously. They are clearly related. Both deal with events that belong in the 'un-ness' category: unexpected, undesirable, unimaginable and often unmanageable situations (Hewitt, 1983). But in academic discourse, "crisis" and "disaster" typically refer to different types of situations, which prompt different questions that require different theories. There is a disaster

\footnotetext{
A. Boin $(\bowtie) \cdot$ S. Kuipers

Leiden University, Leiden, The Netherlands e-mail: boin@fsw.leidenuniv.nl

P.'t. Hart

Utrecht University, Utrecht, The Netherlands
}

research community and a more diffused group of crisis researchers. The concepts 'crisis' and 'disaster' signal different research interests and approaches.

As researchers in both communities can and do draw from each other's work, we think it is important to debate what these key concepts refer to and how they inform research. In this chapter, we focus on what we call the "crisis approach" in academia and position it as a complementary approach to the disaster paradigm presented in this handbook (see in particular Chap. 1 of this Handbook). But first we should discuss how the concepts differ.

We define a disaster as an episodic event that is collectively construed as very harmful (cf. Boin, 2005; Perry \& Quarantelli, 2005). A disaster refers to an event that causes human suffering and infrastructural damage. Disaster researchers used to predominantly study agents of destruction that fall into the category of natural forces such as floods, hurricanes, tsunamis and earthquakes (Stallings, 2005). More recently, they have begun to pay more attention to "man-made" events such as terrorism, ethnic conflicts, economic breakdowns and technological failure (see Erikson, 1994; Kendra \& Wachtendorf, 2016; Perry, this volume). Disaster researchers are interested in prevention and mitigation of these events; they also study the consequences of disasters.

Crisis researchers typically focus on a temporal slice of the process through which a disaster emerges and eventually fades. They are mostly interested in the phase where intervention 
can still limit the effects of an emerging or escalating incident. We define a crisis as a threat that is perceived to be existential in one way or another (cf. Rosenthal, Boin, \& Comfort, 2001). No disaster has materialized just yet, but the prospect is imminent. Speaking of a crisis is in an odd way deeply optimistic: it suggests that the threat in question may still be averted if people, communities, institutions, leaders or systems rise to the challenge. That's why the term "crisis" is usually closely linked to the term "crisis management". This definition gives rise to a particular yet broad-ranging way of academic work that we try to summarize here in terms of 'the crisis approach.'

The crisis approach brings together ideas of vulnerability, risk, threat, trigger, process, response and outcome. It is agnostic to the source of threat: it is applied to such disparate events as 9/11, the Asian tsunami, the swine flu pandemic, Hurricane Katrina, the Deep Water Horizon oil spill, the Fukushima Daiichi nuclear meltdown, the financial breakdown, and Brexit. While it recognizes the importance of prevention and risk management, it accepts the notion that crises can always happen. It advocates the idea that preparation can make the difference between a small incident and a full-blown disaster. It trains our attention on the opportunity dimension of adversity: what is a crisis to some may be an opportunity to others. It accepts that crisis outcomes are socially construed and will likely be contested.

In this chapter, we lay out the various components of the crisis approach. We build the chapter around two sets of questions that seem equally relevant to crisis and disaster researchers. The first set addresses the nature of crisis, inquiring into the causes, characteristics, and consequences of crises. The second set addresses the effectiveness of crisis management. We offer the outlines of a framework that may help assess the performance of crisis managers in a more subtle way than public inquiries and many academic studies often do. We start the chapter off with a discussion of the crisis concept.

\subsection{The Nature of Crisis}

In ancient Greek, the term crisis refers to a critical point, a fork in the road of development, a moment of decision. In medical parlor, a crisis refers to the critical phase of a patient's fight against a deadly threat: will she live or die? In contemporary usage, crisis still combines the grave threat and the escape door: the situation may look bad, but it is not hopeless. In fact, a crisis may open up unforeseen "windows of opportunity" (Kingdon, 1984). This fundamental ambiguity stands in marked contrast to the doom implied by the Greek word for disaster (literally: bad alignment of stars).

We speak of a crisis when a group, organization or community experiences a "serious threat to the basic structures or the fundamental values and norms of a system, which under time pressure and highly uncertain circumstances necessitates making vital decisions (Rosenthal, Charles, \& 't Hart, 1989, p. 10). This definition of crisis allows us to compare a wide variety of adversity: natural disasters and environmental threats, financial meltdowns and terrorist attacks, epidemics and exploding factories, infrastructural breakdown and organizational decline. What all these events have in common is that they create impossible conditions for those who seek to manage a response operation; they force first responders, public managers and political leaders to make urgent decisions while essential information about causes and consequences remains unavailable, unreliable or incomplete. Here we will consider in somewhat more detail the three key components - threat, uncertainty, and urgency - that make up this classic definition.

Crises occur when core values or life-sustaining systems of a community come under threat. Think of widely shared values such as safety and security, welfare and health, integrity and rule of law, which become shaky or even meaningless as a result of (looming) violence, destruction, damage or other forms of adversity. When critical infrastructures fail, the normal functioning of modern society is 
threatened. That is why a natural disaster evokes a deep sense of crisis: deeply embedded values of safety and security for oneself and one's loved ones come under threat (Raphael, 1986, p. 26).

In the crisis approach, the threat agents are less interesting than the resulting experience of threat. This approach is not overly focused on categorizing events in "natural", "man-made" or "terrorist" boxes. It is the perception of threat that matters. A threat may cause widespread fear (even when objectively there may be little to worry about), which will force authorities to act.

Crises induce a sense of urgency. Threats that do not pose immediate problems - think of climate change or future pension deficits - do not induce a widespread sense of crisis. Experts may raise red flags but most politicians (and most people) do not lose sleep over problems with a horizon that exceeds their political life expectancy. Time compression is a critical element of crisis: the threat is here, it is real and must be dealt with now.

In a crisis, the perception of an urgent threat is accompanied by a high degree of uncertainty. This uncertainty pertains both to the nature and the potential consequences of the threat: What is happening and how did it happen? What's next, how bad will it be? More importantly, uncertainty clouds the search for solutions: What can we do? What happens if we select this option? What will others do? How will people react?

This approach recognizes that a crisis is the product of shared perception. People do not always agree whether a threat exists, whether it is urgent and what should be done to mend the threat. This creates room for manipulation. Politicians, stakeholders, media and citizens actively try to create a sense of crisis to further action that would be otherwise impossible; others work just as hard to defuse any talk about crisis to preserve the status quo. A crisis is political in nature.

Two core questions have dominated the study of crisis. The first question pertains to the causes of crisis. Why do systems become unstable? Why do people perceive some situations as a crisis whereas they ignore seemingly similar situations? The second question pertains to crisis management. How should we assess crisis management? What determines the effectiveness of crisis management efforts? The crisis approach comprises a variety of theoretical perspectives to answer these questions. We will now briefly consider the interdisciplinary building blocks of this approach.

\subsubsection{Theoretical Perspectives}

The crisis approach borrows from all social sciences. This rich and fruitful mix of perspectives provides exactly what is needed to understand the complexities and dynamics of crises and crisis management. Let us review how crisis researchers have cherry picked from the various theoretical fields in the search for answers to the research questions formulated above.

The crisis approach shares with the disaster perspective a deep relation with sociology. In sociological terms, a crisis marks the phase during which order-inducing institutions stop to function-the threat of anomy lurks in the background (cf. 't Hart, 1993). It is the moment — to cite Everett Hughes (1946) —when "the cake of custom is broken." Sociologists saw an optimistic lining in the crisis cloud, noting that during a crisis "the attention is aroused and explores the situation with a view to reconstructing modes of activity" (W.I. Thomas cited in Hughes [1946]). This idea of possible renewal has sensitized crisis researchers to the ways in which policymakers and politicians exploit crises to bring about changes that would be impossible in more stable times (Boin, 't Hart, Stern, \& Sundelius, 2016).

A sociological subfield of organization theory produced one of the most powerful theories informing our crisis perspective. In Normal Accidents, Perrow (1999) applied two wholesale sociological concepts (complexity and coupling) to explain organizational breakdown (we will elaborate on Perrow's theory in the next section). This and other similar work in organization theory helped raise a fundamental debate about the 
feasibility and desirability of entrusting dangerous technology to large-scale bureaucracies (Chiles, 2001; La Porte, Perrow, Rochlin, \& Sagan, 1994; Sagan, 1993).

Psychology has always been a source of inspiration to crisis researchers. Through their work, we have learned much about individual decision-making under stress and uncertainty (Coates, 2012; Holsti, 1979; Janis \& Mann, 1977; Kahneman, 2011). Social-psychologists have shown that group decisions do not necessarily compensate for the shortcomings of the stressed individual's decision-making process (Janis, 1982; 't Hart, 1994; 't Hart, Stern, \& Sundelius, 1997).

In addition, psychologists have done important work that helps us understand the relation between human error, technology, organizational culture and the development of crisis (Flin, 1996; Klein, 2001; Reason, 1990). They explain why and how people act on negligible risks (avoiding flying) while they ignore others (smoking; driving without seatbelts) (Gardner, 2008; Pidgeon, Kasperson, \& Slovic, 2003). This explains why well-trained operators make crisis decisions in a very particular way: they compare their situational assessment with mental slides of similar situations (they select the decision that comes with the slide that matches their assessment). Their research helps us understand that crisis decision-making differs quite dramatically from the incremental, semi-rationalistic way often prescribed in textbooks on management and decision-making.

The political science field of International Relations (IR) has traditionally paid much attention to international crises. Crisis scholars in IR - a small minority in this huge field of political scientists-tend to analyze international conflicts in terms of high-level decision-making (Herek, Janis, \& Huth, 1987; Hermann, 1972) as well as dynamic interaction between parties (Brecher, 1993). In explaining the escalation and outcomes of international conflicts, they study how pervasive perceptions, bureau-politics, and small-group dynamics affect the critical decisions made during a crisis (Allison, 1971; George, 1991; Jervis, 1976; Lebow, 1981). This firm body of richly documented studies has taught us much about political leadership behavior in times of crisis.

In the more traditional study of political development, a crisis refers to a necessary phase of disorder in a nation's march toward democracy (see f.i. Almond, Flanagan, \& Mundt, 1973; Linz \& Stepan, 1978; Zimmerman, 1983). The sociological meaning of the term was thus preserved, as political scientists applied it to describe a phase in which established institutions had lost their influence. But the term was infused with a normative meaning, which has made the study of crisis slightly suspect in this field ever since. When political scientists refer to crisis, the automatic question is: whose crisis are we talking about? In more recent years, this question has led to intriguing contributions that stress the subjective nature of crisis and its outcomes.

Business scholars have produced a substantial body of usually rather prescriptive work to prepare managers and MBA-students to deal with reputation damage, shifting markets, fraud, product recalls and other adverse events that threaten the profitability of the firm (Mitroff \& Pauchant, 1990; Pauchant \& Mitroff, 1992). The rising number of books and articles on the topic of business continuity suggests the emergence of a crisis field in its own right. A similar niche has grown on the topic of corporate reputation in crisis (Coombs, 2007; Sellnow, Veil, \& Anthony, 2015). ${ }^{1}$ The "Great Recession", which has held the U.S. and Europe its grip between 2006 and the time of writing, spurned an interdisciplinary effort to understand why this crisis was so badly managed. In addition, the business field has produced many studies that help understand the importance of regulatory environments (or the lack thereof).

In yet another niche - tucked away in the field of communications studies-interesting work is being done on the relation between crisis actors, (political) stakeholders, media and civilians (Fearn-Banks, 1996; Seeger, Selmer, \& Ulmer,

\footnotetext{
${ }^{1}$ The topic of organizational reputation has made headway into the field of political science and public administration as well (Carpenter, 2010).
} 
2003). This body of research helps us understand why sound decisions may or may not help to manage a crisis, depending on the way they are communicated. It helps us understand how media frames shape reporting about crisis (Miller, Roberts, \& LaPoe, 2014), which, in turn, affect general perceptions of the crisis and the authorities managing it (Cross \& Ma, 2015).

Our tour d'horizon would not be complete without mentioning the field of disaster research. The thorough understanding of collective behavior, disaster myths and the pathologies of top-down coordination in times of adversity have proved particularly fruitful to understanding crisis dynamics (see the other chapters of this book for the lessons of disaster research). The recent rediscovery of resilience provides a bridge between issues of vulnerability, challenges of response and controversial outcomes (Aldrich, 2016; Cutter, Ash, \& Emrich, 2014).

These perspectives have helped us to better understand the nature of crisis and the dynamics of crisis management. In the next two sections, we present the key insights generated in the crisis field with regard to key questions formulated above.

\subsection{The Ubiquity of Crisis}

Crises were once explained in terms of bad luck or God's punishment, but this view has become obsolete (Bovens \& 't Hart, 1996, 2016; Quarantelli, 1998; Steinberg, 2000). It is now accepted, at least by scholars, that crises are the result of multiple causes, which interact over time to produce a threat with devastating potential.

This may be somewhat counterintuitive, as it defies the traditional logic of "triggers" and underlying causes. Linear thinking ("big events must have big causes") thus gives way to a more subtle perspective that emphasizes the unintended consequences of increased complexity (Buchanan, 2000). The approach does not seek to identify specific factors that "cause" a crisis. It proposes that escalatory processes undermine a social system's capacity to cope with disturbances. The agents of disturbance may come from anywhere - ranging from earthquakes to human errors - but the ultimate cause of the crisis lies in the inability of a system to deal with the disturbance.

The causes of vulnerability often reside deep within the system. They typically remain unnoticed, or key policy makers fail to attend to them (Turner, 1978). In the process leading up to a crisis, these seemingly innocent factors combine and transform into disruptive forces that come to represent an undeniable threat to the system. These factors are sometimes referred to as pathogens, as they are present long before the crisis becomes manifest (Reason, 1990, 2008).

The notion that crises are an unwanted by-product of complex systems has been popularized by Perrow's (1999) analysis of the nuclear power incident at Three Miles Island. Perrow describes how a relatively minor glitch in the plant was misunderstood in the control room. The plant operators initially thought they understood the problem and applied the required technical response. But as they had actually misinterpreted the warning signal, the response worsened the problem. The increased threat mystified the operators (they could not understand why the problem persisted) and invited an urgent response. By again applying the "right" response to the wrong problem, the operators continued to exacerbate the problem. Finally, someone figured out the correct source of the problem, just in time to stave off a disaster.

The very qualities of complex systems that drive progress lie at the heart of most if not all technological crises. As socio-technical systems become more complex and increasingly connected (tightly coupled) to other (sub)systems, their vulnerability for disturbances increases (Perrow, 1999; Turner, 1978). The more complex a system becomes, the harder it is for anyone to understand it in its entirety. Tight coupling between a system's component parts and with those of other systems allows for the rapid proliferation of interactions (and errors) throughout the system. 
Complexity and lengthy chains of accident causation do not remain confined to the world of high-risk technology. Consider the global financial crises that have rattled the world in recent years (Posner, 2011). Globalization and ICT tightly connect world markets and financial systems. As a result, a minor problem in a seemingly isolated market can trigger a financial meltdown in markets on the other side of the globe. Structural vulnerabilities in relatively weak economies such as Russia, Argentina or Turkey may suddenly "explode" on Wall Street and cause worldwide economic decline. Economic problems in Greece, Spain and Portugal brought the European Union's common market on the verge of breakdown.

The same characteristics can be found in crises that beset low-tech environments such as prisons or sports stadiums. Urban riots, prison disturbances and sports crowd disasters always seem to start off with relatively minor incidents (Waddington (2007) refers to flashpoints). Upon closer inspection, however, it becomes clear that it is a similar mix of interrelated causes that produces major outbursts of this kind.

In the case of prison disturbances, the interaction between guards and inmates is of particular relevance (Boin \& Rattray, 2004). Consider the 1990 riot that all but destroyed the Strangeways prison in Manchester (UK). In the incubation period leading up to the riot, prison guards had to adapt their way of working in the face of budgetary pressure. Inmates did not understand or appreciate this change in staff behavior and subsequently began to challenge staff authority, which, in turn, generated anxiety and stress among staff. As staff began to act in an increasingly defensive and inconsistent manner, prisoners became even more frustrated with staff behavior. A reiterative, self-reinforcing pattern of changing behavior and staff-prisoner conflict set the stage for a riot. A small incident started the riot, which, in turn, touched off a string of disturbances in other prisons. Many civil disturbances between protestors and police seem to unfold according to the same pattern (Goldstone \& Useem, 1999; Smelser, 1962; Waddington, 2007).
All this makes a crisis hard to detect. It is hard to understand the manifold activities and processes that take place in these systems. ${ }^{2}$ Growing vulnerabilities go unrecognized and ineffective attempts to deal with seemingly minor disturbances continue. The system thus "fuels" the lurking crisis. Only a minor "trigger" is needed to initiate a destructive cycle of escalation, which may then rapidly spread throughout the system. Crises may have their roots far away (in a geographical sense) but rapidly snowball through the global networks, jumping from one system to another, gathering destructive potential along the way.

Modern vectors such as globalization, just-in-time delivery chains, increasing volumes of travel and transportation have enhanced the speed and potential scope of crisis escalation. The tight connections between policy systems, business multinationals and internationally oriented communities give rise to crises that are increasingly transboundary (Ansell, Boin, \& Keller, 2010). Think of the 2010 volcanic ash crisis that virtually paralyzed European air transport networks for almost two weeks (Kuipers \& Boin, 2015). The eruption and ash cloud production of the Icelandic Eyjafjallajökull volcano triggered a crisis that rippled across the European continent, causing a mobility crisis for the European economy.

Have modern systems become more vulnerable to breakdown? One might argue that modern society is better than ever equipped to deal with routine failures: great hospitals, computers and telephones, fire trucks and universities, regulation and funds - these factors have helped to minimize the scope and number of crises that were once routine (Wildavsky, 1988). Others argue that the resilience of modern society has deteriorated: when a threat does materialize (say an electrical power outage), modern systems

\footnotetext{
${ }^{2}$ The laws of complex systems are still largely unknown. And the more we learn about the behavior of complex systems, the less we seem to understand. Complexity theorists are busy uncovering the hidden patterns that they say underlie this process, but practical insights (for our purposes at least) have yet to emerge. For an introduction see Buchanan (2000).
} 
suffer most. Students of natural disasters make a similar point: modern society increases its vulnerability to disaster by building in places where history warns not to build (Tierney, 2014). The costs of natural and man-made disasters continue to grow, while scenarios of future crises promise more mayhem. ${ }^{3}$

This approach to crisis holds an important lesson for practitioners: before anything can be done to prevent a crisis from materializing, an emerging threat must be explicitly recognized. There are at least three reasons why many potential crises fail to gain such recognition.

First, threats to shared values or life-sustaining functions cannot always be recognized before their disastrous consequences materialize. As the crisis process begins to unfold, policy makers often do not see anything out of the ordinary. Everything is still in place, even though hidden interactions eat away at the pillars of the system. It is only when the crisis is in full swing and becomes manifest that policy makers can recognize it for what it is.

The second reason is found in the contested nature of crisis. A crisis rarely, if ever, "speaks for itself." The definition of a situation is, as argued above, the outcome of a subjective process. More often than not people will differ in their perception and appreciation of a threat. In fact, we might say that crisis definitions are continuously subjected to the forces of politicization (Edelman, 1977). One man's crisis is another man's opportunity.

The third reason has to do with the closed nature of policy agendas. Even if consensus would exist that a serious threat is emerging, the status of this new problem is far from assured. Governments deal with urgent problems everyday; attention for one problem takes away attention from another. For a threat to be recognized as a crisis, it must gain sufficient societal and political attention to earn a place on overcrowded policy agendas (Birkland, 1997; Bovens \& 't Hart, 1996). ${ }^{4}$

\footnotetext{
${ }^{3}$ Recent scenarios feature radical weather changes, biological terrorism, and asteroid collisions (Bryson, 2003; OECD, 2003, 2011; Schwartz \& Randall, 2003).
}

\subsection{Crisis Management: Crucial Challenges for Leadership}

We define crisis management as the set of efforts aimed at minimizing the impact of an urgent threat. This response typically involves multiple actors. Some of these actors may operate at the strategic (policy-making) level, others more at the operational level (think of police officers, firemen, ambulance drivers, technicians etc.). These worlds are quite distinct in the types of responsibilities actors have and the activities they engage in (Boin \& Renaud, 2013).

Crisis management will differ based on the "knowability" of the situation. Some crises are unique events, leaving both strategic crisis managers and operational first responders with few preconceived ideas as to how to handle the situation. Other crises may offer a variation on a theme: think of hurricanes and floods, or certain infrastructural failures, which may follow familiar patterns even if they differ in important details. For these latter events, specific plans and scenarios may be developed. For events that occur regularly and often, a quantitative basis may exist to allow for risk assessments (calculating what the chances are that a certain event will occur). As uncertainty rises, crisis managers will find risk assessments and disaster plans less useful.

Crisis management is not an easy job. Psychological constraints operate at the individual, group and organizational level. The stress of crisis can impair information management and decision-making in severe ways. A combination of political and media pressure typically makes the jobs of crisis managers harder. Citizens whose lives are affected by critical contingencies expect governments and public agencies to do their utmost to keep them out of harm's way. They expect the officials in charge to make critical decisions and provide direction even in the most difficult circumstances. So do the journalists that produce the stories that help to shape the

\footnotetext{
${ }^{4}$ How and when policymakers recognize (or not) threats is object of research in the policy studies community (Birkland, 1997; Kingdon, 1984).
} 
crisis in the minds of the public. And so do members of parliament, public interest groups, institutional watchdogs and other voices on the political stage that monitor and influence the behavior of leaders. However misplaced, unfair or illusory these expectations may be, it hardly matters. These expectations are real in their political consequences (Thomas \& Thomas, 1928).

Crisis management has become more challenging because the democratic context has changed over the past decades. Analysts agree, for instance, that citizens and politicians alike have become at once more fearful and less tolerant of major hazards to public health, safety and prosperity. The modern Western citizen has little patience for imperfections; he has come to fear glitches and has learned to see more of what he fears. In this culture of fear-sometimes referred to as the "risk society" - the role of the modern mass media is crucial (Beck, 1992).

In contemporary Western society, a crisis sets in motion extensive follow-up reporting, investigations by political forums as well as civil and criminal juridical proceedings. It is not uncommon for public officials and agencies to be singled out as the responsible actors for prevention, preparedness and response failures. Public leaders must defend themselves against seemingly incontrovertible evidence of their incompetence, ignorance or insensitivity. Crisis management therefore should be viewed a deeply controversial and intensely political activity (Edelman, 1977; Habermas, 1975; 't Hart, 1993).

Given these constraints and the nature of the crisis management challenge, one might ask what we can reasonably expect from crisis leaders operating at the strategic level? Research suggests that effective and legitimate crisis management is enhanced by the performance of several managerial functions: early recognition, sense making, decision making and coordination, meaning making, accounting and learning (Boin et al., 2016). Let us now briefly review these functions in somewhat more detail.

\subsubsection{Early Detection}

A crisis seems to pose a straightforward challenge: once a crisis becomes manifest, crisis managers must take measures to deal with its consequences. Reality is much more complex, however. Most crises do not materialize with a big bang; they are the product of escalation. Policymakers must not only recognize from vague, ambivalent, and contradictory signals that some threat is emerging. This means that they have to define the evolving situation and arrive at a collective understanding of its potential scope and effects. Effective crisis management begins with a shared recognition that a threat has emerged which requires immediate attention.

Inquiry reports often give the impression that most crises could have been foreseen. In hindsight, when we all know what happened and why, criticasters wonder how those in charge could have missed so many red flags (Tetlock, 2005; Turner, 1978; Woods, 2005). However, during the emergence of a crisis, the bits of fragmented information that later turn out to be signals cannot be easily distinguished from other 'noise.'

In the literature, we identify two conditions for "foresight" (cf. Turner, 1978). The first condition pertains to extensive experience among first responders and system operators with incidents and their dynamics. Apparently, experienced fire fighters can develop a keen sense of impending danger (Klein, 2001). Likewise, operators develop an ability to recognize deviations in complex but known processes. Roe and Schulman (2008) show how vulnerabilities in organizational design and high risk infrastructures design are compensated by the people who manage for high reliability, even during peak demand times or periods of stress. The second is organizational. Organizations should stimulate rapid detection of impending threats (Weick \& Sutcliffe, 2002). They should put a premium on continuous vigilance and on a collective willingness to act on faint signals, tolerate false 
alarms and encourage voluntary admissions of failures and near-misses.

\subsubsection{Sense Making}

However penetrating the events that trigger a crisis - jet planes hitting skyscrapers, thousands of people found dead in mass graves - a uniform picture of the events rarely emerges: do they constitute a tragedy, an outrage, perhaps a punishment, or, inconceivably, a blessing in disguise? Crisis managers will have to determine how threatening the events are, to what or whom, what their operational and strategic parameters are, and how the situation will develop in the period to come. Signals come from all kinds of sources: some loud, some soft, some accurate, some widely off the mark. But how to tell which is which? How to distill cogent signals from the noise of crisis?

Rational information processing is very hard under conditions of deep uncertainty (Coates, 2012; Kahneman, 2011; Reason, 2008). The bewildering pace, ambiguity and complexity of crisis can easily overwhelm normal modes of situation assessment. Stress may further impair sense-making abilities. The organizations in which crisis managers typically function tend to produce additional barriers to collective agreement on a common operational picture of the situation.

Effective sense-making is hard without an established and practiced routine that allows strategic crisis managers to process information, circulate it among the relevant people and consider their feedback, create a common operational picture, analyze mid- and long term consequences, and articulate and adequately address specific information needs. Even organizations (think of NASA or the worldwide network of national and international centers of disease control) with an extensive sense-making machinery in place, struggle to arrive at a shared picture of the situation in time.

An important new trend is the ability of first responders, humanitarian relief organizations and affected citizens - who happen to be present at ground zero - to provide information and engage directly in sense making by means of social media. Innovative tools, such as UNOCHA's humanitarian aid app, and emerging theoretical approaches focus on employing a "knowledge commons" to support crisis leaders in extreme events (Comfort \& Okada, 2013). Using social media tools and applications, citizens play an increasingly central role in disaster response (Sabou and Klein, 2016; Vieweg, Palen, Liu, Hughes, \& Sutton, 2008; Yates \& Paquette, 2011). This emerging involvement of ad hoc citizen networks employing new media brings a new set of actors and perspectives to the sense making table, for better and for worse. They can provide crucial information but also add to the stream of unverified rumors and thereby critically skew the collective assessment of what is going on. The leadership challenge is to benefit from the possibilities these upcoming information sources and networks without falling prey to its potential downsides.

\subsubsection{Making Critical Decisions}

Responding to crises often confronts governments and public agencies with pressing choice opportunities. These can be of many kinds. The needs and problems triggered by the onset of crisis may be so big that the scarce resources available will have to be prioritized. This is much like politics as usual except that in crisis circumstances the disparities between demand and supply of public resources are much bigger, the situation remains unclear and volatile, and the time to think, consult and gain acceptance for decisions is highly restricted. Crises also confront governments and leaders with issues they do not face on a daily basis, for example concerning the deployment of the military, the use of lethal force, or the radical restriction of civil liberties.

The classic example of crisis decision-making is the Cuban Missile Crisis (1963), during which U.S. President John F. Kennedy was presented with pictures of Soviet missile installations under construction in Cuba. The photos conveyed a geostrategic reality in the making that Kennedy 
considered unacceptable, and it was up to him to decide what to do about it. Whatever his choice from the options presented to him by his advisers an air strike, an invasion of Cuba, a naval blockade - and however hard it was to predict the exact consequences, one thing seemed certain: the final decision would have a momentous impact on Soviet-American relations and possibly on world peace. Crisis decision-making is making hard calls, which involve tough value trade-offs and major political risks (Brecher, 1993; Janis, 1989).

Many pivotal crisis decisions are not taken by individual leaders or by small informal groups of senior policy makers. They emerge from various alternative loci of decision making and coordination (McConnell, 2003; 't Hart, Rosenthal, \& Kouzmin, 1993). In fact, the crisis response in modern society is best characterized in terms of a network. This is not necessarily counterproductive, many leaders have learned, as delegation of decision-making authority down the line usually enhances resilience rather than detracting from it.

\subsubsection{Crisis Coordination}

Crises typically require intense cooperation in a network of organizations that may well be new to each other (Boin \& 't Hart, 2012; Boin \& Bynander, 2015). Vertical and horizontal cooperation must be orchestrated to accomplish a state of coordinated behavior. Because a situation can be urgent and threatening but the network of partners is often not hierarchically related, orchestrating a response requires striking a careful balance between persuasion and "command and control." Persuasion does usually not suffice to reach a state of optimal cooperation. Top down command can easily back-fire.

After all, each decision must be implemented by a set of organizations; only when these organizations work together is there a chance that effective implementation will happen. Getting public bureaucracies to adapt to crisis circumstances is a daunting - some say impossible - task in itself. Most public organizations were originally designed to conduct routine business in accordance with such values as fairness, lawfulness and efficiency. The management of crisis, however, requires flexibility, improvisation, redundancy, and the breaking of rules.

Coordination is not a self-evident feature of crisis management operations. The question of who is in charge typically arouses great passions. In disaster studies, the "battle of the Samaritans" is a well-documented phenomenon: agencies representing different technologies of crisis coping find it difficult to align their actions. Moreover, a crisis does not make the public suddenly "forget" the sensitivities and conflicts that governed the daily relations between authorities and others before the crisis. Trust and social capital therefore receive increasing attention in the disaster literature on effective response and recovery operations (Aldrich, 2012).

Disaster researchers see self-organization as a central feature of coordination. Disaster-stricken communities, local organizations and individual victims can be surprisingly creative and adaptive. Their ad hoc nodes of cooperation may even be best suited to local needs (Aldrich, 2012; Carr, 1932; Comfort \& Okada, 2013; Drabek, 1985). The effectiveness of self-organization instructs central authorities to hold back (Boin \& Bynander, 2015). Such situations are best served by "enabling leadership" (Nooteboom \& Termeer, 2015). Effective leaders are "asking more than telling, requesting rather than ordering, delegating and decentralizing rather than narrowing and centralizing" (Quarantelli, 1988:382). If, however, network parties clash or local capacity is completely overwhelmed, central officials should take charge and intervene.

\subsubsection{Meaning Making}

In a crisis, leaders are expected to reduce uncertainty and provide an authoritative account 
of what is going on, why it is happening and what needs to be done. When they have made sense of the events and have arrived at some sort of situational appraisal and made strategic policy choices, leaders must get others to accept their definition of the situation. They must impute "meaning" to the unfolding crisis in such a way that their efforts to manage it are enhanced. If they don't, or if they do not succeed at it, their decisions will not be understood nor respected. If other actors in the crisis succeed in dominating the meaning-making process, the ability of incumbent leaders to decide and maneuver is severely constrained.

Two problems often recur. First, public leaders are not the only ones trying to frame the crisis. Their messages coincide and compete with those of other parties, who hold other positions and interests, who are likely to espouse various alternative definitions of the situation and advocate different courses of action. Censoring them is hardly a viable option in a democracy.

Second, authorities often cannot provide correct information right away. They struggle with the mountains of raw data (reports, rumors, pictures) that are quickly amassed when something extraordinary happens. Turning them into a coherent picture of the situation is a major challenge by itself. Getting it out to the public in the form of accurate, clear and actionable information requires a major public relations effort. This effort is often hindered by the aroused state of the audience: people whose lives are deeply affected tend to be anxious if not stressed. Moreover, they do not necessarily see the government as their ally. And pre-existing distrust of government does not evaporate in times of crisis.

\subsubsection{Accounting for Performance}

In a democratic polity, crisis leaders will have to render account for what has happened and what government organizations have done in response. If they gain acceptance for their account, legitimacy of public government is effectively preserved (Boin, McConnell, \& 't Hart, 2008).
The burden of proof in accountability discussions lies with leaders: they must establish beyond doubt that they cannot be held responsible for the occurrence or escalation of a crisis. These accountability debates can easily degenerate into "blame games" with a focus on identifying and punishing "culprits" rather than discursive reflection about the full range of causes and consequences. ${ }^{5}$ The challenge for leaders is to cope with the politics of crisis accountability without resorting to undignified and potentially self-defeating defensive tactics of blame avoidance that only serve to prolong the crisis by transforming it into a political confrontation at knife's edge.

Crisis leaders can be competent and conscientious, but that alone says little about how their performance will be evaluated when the crisis is over. Policymakers and agencies that failed to perform their duties prior to or during the critical stages need not despair, however: if they "manage" the political game of the crisis aftermath well, they may prevent losses to their reputation, autonomy, and resources. Crises have winners and losers. The political (and legal) dynamics of the accountability process determines which crisis actors end up where (Brändström \& Kuipers, 2003; Hood, 2010; Resodihardjo, Carroll, Van Eijk, \& Maris, 2016).

\subsubsection{Learning Lessons}

A crisis offers a reservoir of potential lessons for contingency planning and training for future crises. One would expect all those involved to study these lessons and feed them back into organizational practices, policies and laws.

Lesson-drawing is one of the most underdeveloped aspects of crisis management (Broekema, 2016; Lagadec, 1997; Stern, 1997). In addition to cognitive and institutional barriers to learning, lesson-drawing is constrained by the

\footnotetext{
${ }^{5}$ Although much more pronounced today, the tendency to search for culprits following the occurrence of disaster and crisis is age old, see Drabek and Quarantelli (1967) as well as Douglas (1992).
} 
role of these lessons in determining the impact that crises have on a society. Crises become part of collective memory, a source of historical analogies for future leaders (Khong, 1992; Sturken, 1997). The political depiction of crisis as a product of prevention and foresight failures would force people to rethink the assumptions on which preexisting policies and rule systems rested. Other stakeholders in the game of crisis-induced lesson-drawing might seize upon the lessons to advocate measures and policy reforms that incumbent leaders reject. Leaders thus have a big stake in steering the lesson-drawing process in the political and bureaucratic arenas. The crucial challenge here is to achieve a dominant influence on the feedback stream that crises generate into preexisting policy networks and public organizations.

The documentation of these inhibiting complexities has done nothing to dispel the near-utopian belief in crisis opportunities that is found not only in academic literature, but also in popular wisdom (Boin \& 't Hart, 2003). A crisis is seen as a good time to clean up and start anew. Crises then represent discontinuities that must be seized upon - a true test of leadership, the experts claim. So most people are not surprised to see sweeping reforms in the wake of crisis: that will never happen again! They intuitively distrust leaders who claim bad luck and point out that their organizations and policy have a great track record.

Crises tend to cast long shadows upon the political systems in which they occur. It is only when we study these longer term processes that we are able to assess the full impact of crises. Unfortunately, such studies are rare (but see Birkland, 1997; Kurtz \& Browne, 2004). Most studies of the "crisis aftermath" of emergencies have been about community reconstruction, individual and collective trauma, and legal battles. We need to complement these studies by taking a broader macro-social perspective that looks at collective "learning" for an entire nation, polity or society in the aftermath of crisis (Broekema, 2016). It remains an open question if crises tend to serve as triggers of systemic change or if they serve to forestall such change, and to what extent these processes can be channeled by good crisis governance.

\subsection{Conclusion: The Crisis Approach Reconsidered}

The crisis approach outlined in this chapter provides a framework for understanding the dynamic evolution of crisis and the prospects for public management of urgent threats. The approach adopts a long time line, which makes it possible to trace a crisis from its early roots to its burial in public memory. It admonishes the research community to complement operational perspectives with political perspectives. Most importantly, perhaps, is its capacity to tease out the interplay between crisis dynamics and crisis outcomes.

Two lessons seem of particular relevance to practitioners. First, one should accept that even the richest and most competent government imaginable can never guarantee that major disruptions will not occur. Policy makers cannot escape the dilemmas of crisis response by banking on crisis prevention. Crisis prevention is a necessary and indeed vitally important strategy, but it pertains only to known emergencies - those that happened before. This requires a strategy of resilience (Wildavsky, 1988). This lesson resonates with key insights in the disaster field.

The second lesson reminds us that crisis is a label, a semantic construction people use to characterize situations or epochs that they somehow regard as extraordinary, volatile and potentially far-reaching in their negative implications. The intensity or scope of a crisis is thus not solely determined by the nature of the threat, the level of uncertainty, or the time available to decision-makers. A crisis is to a considerable extent what people - influenced by the inevitable mass media onslaught following an unscheduled event - make of it.

Why people collectively label and experience a situation as a crisis remains somewhat of a mystery. Physical facts, numbers and other seemingly objective indicators are important factors, but they are not decisive. A flood that 
kills 200 people is a more or less routine emergency in Bangladesh, but it would be experienced as a major crisis in, let's say, Miami or Paris. Crises are in the eye of the beholder. It is people's frames of reference, experience and memory, values and interests that determine their perceptions of crisis. A sense of "collective stress" results not just from some objective threat, but also from the intricate interaction between events, individual perceptions, media representations, political reactions, and government efforts at "meaning making."

This process of collective understanding is one of escalation and de-escalation. It is subject to the influence of actors who have a stake in playing up a crisis mood, or playing it down. And this is exactly what happens when unexpected incidents or major disruptions are predicted or actually occur: different political, bureaucratic, societal and international stakeholders will not only form their own picture of the situation and classify it in terms of threats and opportunities, but many of them will actively seek to influence the public perception of the situation. Once a particular definition of the situation has taken hold in mass media and political discourse, it becomes a political reality that policymakers have to take into account and act upon. Initial definitions tend to be persistent.

An effective crisis response will inevitably require a two-pronged strategy: dealing with the events "on the ground" (whether literally as in civil emergencies or, metaphorically, as in a currency or stock market crisis); and dealing with the political upheaval and instability triggered by these events. Neglecting one or the other is detrimental to any attempt to exercise public leadership in a crisis.

These lessons help us to flag three challenges for further research. First, much work remains to be done on the understanding of crisis dynamics. If crises cannot be prevented, we must learn to recognize them in time. Early warning can only work if it builds on a solid theory of crisis development. Second, researchers need to invest in a better understanding of resilience (Duit, 2016). Crisis researchers tend to agree (with disaster researchers we should note) that resilience may be one of the key strategies to deal with system breakdowns. Much more systematic work needs to be done on the identification of mechanisms that provide for resilient societies (Comfort, Boin, \& Demchak, 2010). Third, research could benefit our understanding of the tenuous relation between crisis and change: which type of crises and disasters open a window for structural change (and what must be done to exploit that opportunity)?

These research challenges would benefit from a close working relation between crisis and disaster scholars. Both communities have rich research traditions with regard to these questions. Both communities draw from each other's empirical and theoretical findings, but interdisciplinary research - bringing both communities together in joint research - has been quite rare. Crisis scholars are deeply indebted to the work of disaster colleagues such as Joe Scanlon, Russell Dynes, Henry Quarantelli and Kathleen Tierney. Disaster researchers, in turn, increasingly make use of current work done by crisis researchers. Our chapter aims to further the blurring of boundaries still separating these fields.

\section{References}

Aldrich, D. (2012). Building resilience: Social capital in post-disaster recovery. Chicago: University of Chicago Press.

Aldrich, D. (2016). It's who you know: Factors driving recovery from Japan's 11 March 2011 disaster. Public Administration, 94(2), 399-413.

Allison, G. T. (1971). Essence of decision: Explaining the Cuban missile crisis. Boston: Little Brown.

Almond, G. A., Flanagan, S., \& Mundt, R. (Eds.). (1973). Crisis, choice and change: Historical studies of political development. Boston, MA, USA: Little Brown.

Ansell, C., Boin, A., \& Keller, A. (2010). Managing transboundary crises: Identifying the building blocks of an effective response system. Journal of Contingencies and Crisis Management, 18(4), 195-207.

Beck, U. (1992). Risk society: Towards a new modernity. London: Sage Publications.

Birkland, T. (1997). After disaster: Agenda-setting, public policy, and focusing events. Washington, DC, USA: Georgetown University Press.

Boin, A. (2005). Disaster research and future crises: Broadening the research agenda. International Journal of Mass Emergencies and Disasters, 23(3), 199-214. 
Boin, A., \& Bynander, F. (2015). Explaining success and failure in crisis coordination. Geografiska Annaler: Series A, Physical Geography, 97(1), 123-135.

Boin, A., \& 't Hart, P. (2003). Public leadership in times of crisis: Mission Impossible? Public Administration Review, 63(6), 544-553.

Boin, A., \& 't Hart, P. (2012). Aligning executive action in times of adversity: The politics of crisis coordination. In M. Lodge \& K. Wegrich (Eds.), Executive politics in times of crisis (pp. 179-196). Houndmills: Palgrave.

Boin, A., 't Hart, P., Stern, E., \& Sundelius, B. (2016). The politics of crisis management: Public leadership under pressure (2nd ed.). Cambridge: Cambridge University Press.

Boin, A., McConnell, A. \& 't Hart, P. (eds.) (2008). Governing after crisis: The politics of investigation, accountability and learning. Cambridge: Cambridge University Press.

Boin, A., \& Rattray, W. A. R. (2004). Understanding prison riots: Towards a threshold theory. Punishment \& Society, 6(1), 47-65.

Boin, A., \& Renaud, C. (2013). Orchestrating joint sense making across levels: Challenges and requirements for crisis leadership. Journal of Leadership Studies, 7(3), 41-46.

Bovens, M., \& 't Hart, P. (1996). Understanding policy fiascoes. New Brunswick: Transaction Publishers.

Bovens, M., \& 't Hart, P. (2016). Revisiting the study of policy failures. Journal of European Public Policy, 23 (5), 653-666.

Brändström, A., \& Kuipers, S. L. (2003). From "normal incidents" to political crises: Understanding the selective politicization of policy failures. Government and Opposition, 38, 279-305.

Brecher, M. (1993). Crises in world politics: Theory and reality. Oxford: Pergamon Press.

Broekema, W. (2016). Crisis-induced learning and issue politicization in the EU: The Braer, Sea Empress, Erika, and Prestige oil spill disasters. Public Administration, 94(2), 381-398.

Bryson, B. (2003). A short history of nearly everything. New York, NY, USA: Broadway Books.

Buchanan, M. (2000). Ubiquity: Why catastrophes happen. New York, NY, USA: Three Rivers Press.

Carpenter, D. (2010). Reputation and power: Organizational image and pharmaceutical regulation at the FDA. Princeton, NJ, USA: Princeton University Press.

Carr, L. (1932). Disaster and the sequence-pattern concept of social change. American Journal of Sociology, 38, 207-218.

Chiles, J. R. (2001). Inviting disaster: Lessons from the edge of technology. New York, NY, USA: Harper Business.

Coates, J. (2012). The hour between dog and wolf: Risk-taking, gut feelings and the biology of boom and bust. London: Fourth Estate.

Comfort, L. K., Boin, A., \& Demchak, C. (Eds.). (2010). Designing resilience for extreme events. Pittsburgh, PA, USA: Pittsburgh University Press.
Comfort, L. K., \& Okada, A. (2013). Emergent leadership in extreme events: A knowledge commons for sustainable communities. International Review of Public Administration, 18(1), 61-77.

Coombs, T. (2007). Protecting organizational reputation during crisis: The development of a situational crisis communications theory. Corporate Reputation Review, 10(3), 163-176.

Cross, M., \& Ma, X. (2015). EU crises and integrational panic: The role of the media. Journal of European Public Policy, 22(8), 1053-1070.

Cutter, S. L., Ash, K. D., \& Emrich, C. T. (2014). The geographies of community disaster resilience. Global Environmental Change, 29, 65-77.

Douglas, M. (1992). Risk and blame: Essays in cultural theory. London: Routledge.

Drabek, T. E. (1985). Managing the emergency response. Public Administration Review, 45, 85-92.

Drabek, T. E., \& Quarantelli, E. L. (1967). Scapegoats, villains, and disasters. Transaction, 4, 12-17.

Duit, A. (2016). Resilience thinking: Lessons for public administration. Public Administration, 94(2), 364-380.

Edelman, M. J. (1977). Political language: Words that succeed and policies that fail. New York, NY, USA: Academic Press.

Erikson, K. (1994). A new species of trouble: Explorations in disaster, trauma and community. New York, NY, USA: W. W. Norton \& Company.

Fearn-Banks, K. (1996). Crisis communications: A casebook approach. Mahwah: Lawrence Erlbaum Associates.

Flin, R. (1996). Sitting in the hot seat: Leaders and teams for critical incidents. Chichester: Wiley.

Gardner, D. (2008). The science offear: Why we fear the things we shouldn't and put ourselves in greater danger. New York, NY, USA: Dutton.

George, A. L. (Ed.). (1991). Avoiding war: Problems of crisis management. Boulder, CO, USA: Westview Press.

Goldstone, J. A., \& Useem, B. (1999). Prison riots as micro revolutions: An extension of state-centered theories of revolution. American Journal of Sociology, 104, 985-1029.

Habermas, J. (1975). Legitimation crisis. Boston, MA, USA: Beacon Press.

Herek, G. M., Janis, I. L., \& Huth, P. (1987). Decision making during international crises: Is quality of process related to outcome? Journal of Conflict Resolution, 31(2), 203-226.

Hermann, C. F. (Ed.). (1972). International crises: Insights from behavioral research. New York, NY, USA: The Free Press.

Hewitt, K. (Ed.). (1983). Interpretations of calamity. London: Allen \& Unwin.

Holsti, O. R. (1979). Theories of crisis decision making. In P. G. Lauren (Ed.), Diplomacy: New approaches in history, theory, and policy (pp. 99-136). New York, NY, USA: The Free Press.

Hood, C. (2010). The blame game: Spin, bureaucracy and self-preservation in government. Princeton, NJ, USA: Princeton University Press. 
Hughes, E. C. (1946). Institutions in process. In A. McClung Lee (Ed.), New outline of the principles of sociology (pp. 236-247). New York, NY, USA: Barnes \& Noble, Inc.

Janis, I. L. (1982). Groupthink. Boston, MA, USA: Houghton Mifflin.

Janis, I. L. (1989). Crucial decisions: Leadership in policymaking and crisis management. New York, NY, USA: The Free Press.

Janis, I. L., \& Mann, L. (1977). Decision-making: A psychological analysis of conflict, choice and commitment. New York, NY, USA: The Free Press.

Jervis, R. (1976). Perception and misperception in international politics. Princeton, NJ, USA: Princeton University Press.

Kahneman, D. (2011). Thinking, fast and slow. London: Allen Lane.

Kendra, J., \& Wachtendorf, T. (2016). American Dunkirk: The waterborne evacuation of Manhattan on 9/11. Philadelphia: Temple University Press.

Khong, Y. F. (1992). Analogies at war: Korea, Munich, Dien Bien Phu, and the Vietnam decisions of 1965. Princeton, NJ, USA: Princeton University Press.

Kingdon, J. (1984). Agendas, alternatives and public policies. Boston, MA, USA: Little, Brown and Co.

Klein, G. (2001). Sources of power: How people make decisions (7th ed.). London: The MIT Press.

Kuipers, S. L., \& Boin, R. A. (2015). Exploring the EU's role as transboundary crisis manager: The facilitation of sense-making during the Ash-crisis. In R. Bossong \& H. Hegemann (Eds.), European civil security governance: Diversity and cooperation in crisis and disaster management (pp. 191-210). Basingstoke: Palgrave Macmillan.

Kurtz, R. S., \& Browne, W. P. (2004). Crisis management, crisis response: An introduction to the symposium. Review of Policy Research, 21, 141-143.

La Porte, T., Perrow, C., Rochlin, G., \& Sagan, S. (1994). Systems, organizations, and the limits of safety: A symposium. Journal of Contingencies and Crisis Management, 2(4), 205-240.

Lagadec, P. (1997). Learning processes for crisis management in complex organizations. Journal of Contingencies and Crisis Management, 5, 24-31.

Lebow, R. N. (1981). Between peace and war: The nature of international crisis. Baltimore, MD, USA: Johns Hopkins University Press.

Linz, J. J., \& Stepan, A. C. (Eds.). (1978). The breakdown of democratic regimes. Baltimore, MD, USA: Johns Hopkins University Press.

McConnell, A. (2003). Overview: Crisis management, influences, responses and evaluation. Parliamentary Affairs, 56, 363-409.

Miller, A., Roberts, S., \& LaPoe, V. (2014). Oil and water: Media lessons from Hurricane Katrina and the Deepwater Horizon disaster. Jackson, MS, USA: University Press of Mississippi.

Mitroff, I. I., \& Pauchant, T. C. (1990). We're so big and powerful nothing bad can happen to us. New York, NY, USA: Carol.
Nooteboom, S., \& Termeer, C. (2015). Strategies of complexity leadership in governance systems. International Review of Public Administration, 18(1), 2540.

Organization for Economic Cooperation and Development. (2003). Emerging risks in the 21st century: An agenda for action. Paris: OECD.

Organization for Economic Cooperation and Development. (2011). Future global shocks: Improving risk governance. Paris: OECD.

Pauchant, T. C., \& Mitroff, I. I. (1992). Transforming the crisis-prone organization: Preventing individual, organizational and environmental tragedies. San Francisco, CA, USA: Jossey-Bass.

Perrow, C. (1999). Normal accidents: Living with high-risk technologies. Princeton, NJ, USA: Princeton University Press (second edition).

Perry, R. W., \& Quarantelli, E. L. (Eds.). (2005). What is a disaster? New answers to old questions. Philadelphia: Xlibris Press.

Pidgeon, N., Kasperson, R. E., \& Slovic, P. (Eds.). (2003). The social amplification of risk. Cambridge: Cambridge University Press.

Posner, R. A. (2011). A failure of capitalism. Cambridge, MA: Harvard University Press.

Quarantelli, E. L. (1988). Disaster crisis management: A summary of research findings. Journal of Management Studies, 25(4), 373-385.

Quarantelli, E. L. (Ed.). (1998). What is a disaster? Perspectives on the question. London: Routledge.

Raphael, B. (1986). When disaster strikes: How individuals and communities cope with catastrophe. New York, NY, USA: Basic Books.

Reason, J. (1990). Human error. New York, NY, USA: Cambridge University Press.

Reason, J. (2008). The human contribution: Unsafe acts, accidents and heroic recoveries. London: Routledge.

Resodihardjo, S. L., Carroll, B. J., Van Eijk, C. J. A., \& Maris, S. (2016). Why traditional responses to blame games fail: The importance of context, rituals, and sub-blame games in the face of raves gone wrong. Public Administration, 94(2), 350-363.

Roe, E., \& Schulman, P. (2008). High reliability management: Operating on the edge. Stanford, CA, USA: Stanford University Press.

Rosenthal, U., Boin, R. A., \& Comfort, L. K. (Eds.). (2001). Managing crises: Threats, dilemmas, opportunities. Springfield: Charles C. Thomas.

Rosenthal, U., Charles, M. T., \& 't Hart, P. (Eds.). (1989). Coping with crisis: The management of disasters, riots and terrorism. Springfield: Charles C. Thomas.

Sabou, J., \& Klein, S. (2016). How virtual and technical communities can contribute to U.N. led humanitarian relief operations: Boundary spanning and the exploration of collaborative information practices. In Proceedings of the 20th Pacific Asia Conference on Information Systems (PACIS 2016), Cahiyi, Taiwan.

Sagan, S. D. (1993). The limits of safety: Organizations, accidents and nuclear weapons. Princeton, NJ, USA: Princeton University Press. 
Schwartz, P., \& Randall, D. (2003). An abrupt climate change scenario and its implications for U.S. National Security. Pentagon Report.

Seeger, M. W., Sellnow, T. L., \& Ulmer, R. R. (2003). Communication and organizational crisis. Westport: Praeger.

Sellnow, T. N., Veil, S. R., \& Anthony, K. (2015). Experiencing reputational synergy of success and failure through organizational learning. In C. Carroll (Ed.), Handbook of communication and corporate reputation (pp. 235-248). Oxford: Wiley-Blackwell Publishing.

Smelser, N. J. (1962). Theory of collective behavior. London: Routledge.

Stallings, R. A. (2005). Disaster, Crisis, Collective Stress and Mass deprivation. In R. W. Perry \& E. L. Quarantelli (Eds.), What is a disaster: New answers to old questions (pp. 237-274). Philadelphia: XLibris.

Steinberg, T. (2000). Acts of god: The unnatural history of natural disaster in America. New York, NY, USA: Oxford University Press.

Stern, E. K. (1997). Crisis and learning: A balance sheet. Journal of Contingencies and Crisis Management, 5, 69-86.

Sturken, M. (1997). Tangled memories: The Vietnam war, the Aids epidemic, and the politics of remembering. Berkeley: University of California Press.

't Hart, P. (1993). Symbols, rituals and power: The lost dimension in crisis. Journal of Contingencies and Crisis Management, 1(1), 36-50.

't Hart, P. (1994). Groupthink in government: A study of small groups and policy failure. Boston. MA, USA: Johns Hopkins University Press.

't Hart, P., Rosenthal, U., \& Kouzmin, A. (1993). Crisis decision making: The centralization thesis revisited. Administration and Society, 25, 12-45.

't Hart, P., Stern, E. K., \& Sundelius, B. (Eds.). (1997). Beyond groupthink: Political group dynamics and foreign policymaking. Ann Arbor, MI, USA: University of Michigan Press.

Tetlock, P. (2005). Expert political judgment: How good is it? How can we know?. Princeton, NJ, USA: Princeton University Press.

Thomas, W., \& Thomas, D. (1928). The child in America: Behavior problems and programs. New York, NY, USA: A. A. Knopf.

Tierney, K. (2014). The social roots of risk: Producing disasters, promoting resilience. Stanford, CA, USA: Stanford University Press.

Turner, B. A. (1978). Man-made disasters. London: Wykeham.

Vieweg, S., Palen, L., Liu, S., Hughes, A., \& Sutton, J. (2008). Collective intelligence in disaster: An examination of the phenomenon in the aftermath of the Virginia Tech Shooting. In Proceedings of the 5th International ISCRAM Conference, Washington DC, May 2008.

Waddington, D. P. (2007). Policing public disorder: Theory and practice. Willan: Cullompton.

Weick, K. E., \& Sutcliffe, K. M. (2002). Managing the unexpected: Assuring high performance in an age of complexity. San Francisco, CA, USA: Jossey-Bass.

Wildavsky, A. B. (1988). Searching for safety. Berkeley: University of California Press.

Woods, D. D. (2005). Creating foresight: Lessons for enhancing resilience from Columbia. In W. H. Starbuck \& M. Farjoun (Eds.), Organization at the limit: Lessons from the Columbia disaster (pp. 289-308). Oxford: Blackwell Publishing.

Yates, D., \& Paquette, S. (2011). Emergency knowledge management and social media technologies: A case study of the 2010 Haitian earthquake. International Journal of Information Management, 31, 6-13.

Zimmerman, E. (1983). Political violence, crises and revolutions: Theories and research. Cambridge: Schenkman. 